\title{
Investigation of surface modifications in ethylene propylene diene monomer (EPDM) rubber due to tracking under a.c. and d.c. voltages
}

\author{
R SARATHI* and UMA MAHESWAR RAO \\ Department of Electrical Engineering, Indian Institute of Technology, Chennai 600 036, India
}

MS received 16 July 2001

\begin{abstract}
In the present work, tracking phenomena has been studied with the ethylene propylene diene monomer (EPDM) material under the a.c. and d.c. voltages, with ammonium chloride/acid rain solution as the contaminant. It is noticed that the tracking time depends on the conductivity and flow rate of the contaminant. The physico-chemical analyses viz. wide angle X-ray diffraction (WAXD), thermo-gravimetric differential thermal analysis (TG-DTA) and the differential scanning calorimetry (DSC) studies, were carried out and it was concluded that the tracking process is a surface degradation process. The tracking time is different for a.c. and d.c. voltages.
\end{abstract}

Keywords. EPDM; tracking surface; degradation; acid rain; WAXD; DSC; TG-DTA.

\section{Introduction}

Polymer materials are currently being used as high voltage outdoor insulation structure in distribution and transmission power systems, because of their better dielectric properties, light weight and cost when compared to the porcelain or glass insulators. Although glass and ceramic were the preferred materials for insulators, bushings, cable terminations and surge arresters for many years, their high surface energy rendered them wettable when exposed to environmental pollution, causing an increase in leakage current thereby leading it to various problems. When selecting the insulator, there are choices that encompass both material properties and design. There is an ever-increasing interest in power industry worldwide, to understand the degradation process and the performance characteristics of polymer insulating material in severe pollution conditions like acid rain. The single largest problem yet to be overcome is the tracking and erosion of outdoor insulation structure.

Tracking, which is a peculiar phenomenon, occurs on the surface because of the creepage discharge resulting from surface contamination. It varies with surface field intensity, surface current magnitude and the state of discharge thereby induced, all of which are due to surface wetting and the degree of contamination. Once tracking occurs, the surface electrical insulation property is lost completely and it never recovers. In order to improve reliability and performance of insulation material, the tracking phenomena is being investigated worldwide.

*Author for correspondence
Some polymeric materials including silicon rubber and ethylene propylene diene monomer (EPDM) maintain their hydrophobic surface properties in the presence of pollutants over the surface of the insulators. Most of the tracking studies carried out in polymer insulation are under a.c. voltage (Hasegawa et al 1997; Yoshimura 1997). In recent times, the d.c. power transmission has become preferable mode of power transmission. It has become necessary to understand the tracking phenomena with insulation material, under the d.c. voltages. In fact, due to greater accumulation of contamination over the insulators under d.c. voltages, the problem of tracking phenomena is even more severe compared to a.c. voltage and the tracking phenomena under the d.c. voltages has to be thoroughly understood.

EPDM is used as a construction material for the insulators. It offers hydrophobicity for a long time. The long term maintenance of the hydrophobicity is attributed due to its chemical stability and hydrophobicity recovery phenomena resulting from diffusion of low molecular weight silicon polymers (Deng and Hackam 2000). The hydrophobicity of polymers provides a high electrical surface resistance, but then it is reduced by water absorption during ageing with increasing environmental temperature and contamination buildup.

Having known all this, in the present work, more care has been taken to understand the tracking phenomena in EPDM material, by carrying out experiments as per IEC587 , under a.c. and d.c. voltages, with acid rain $/ \mathrm{NH}_{4} \mathrm{Cl}$ as contaminants. A separate experimental methodology has been adopted, to understand the influence of acids on the surface condition of the polymeric material and on the tracking phenomena. Mechanism of failure due to tracking under the d.c. voltages was discussed. In addition, the 


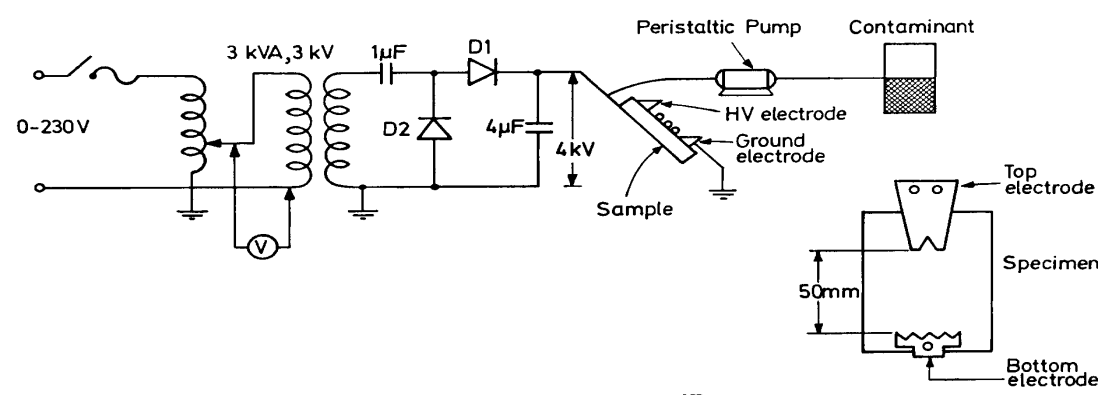

Figure 1. Experimental setup.

residues formed due to tracking and the surface condition of the tracking formed zone were analysed using wide angle-X-ray diffraction (WAXD), differential scanning calorimetry (DSC) and by thermogravimetric differential thermal analysis (TG-DTA) studies.

\section{Experimental}

There is no regular test procedure to carry out a tracking test under the d.c. voltage application. In the present work, tracking test was carried out following IEC-587 (1984) test method, which is adopted for a.c. voltage application. The specimen used in the present work is EPDM material. The gap distance between the top and the bottom electrode adjusted to be equal to $50 \mathrm{~mm}$. The schematic diagram of the experimental setup and the electrode configuration used in the present work are shown in figure 1 for the d.c. voltages. If the sample is directly connected to the transformer without the rectifier circuit the a.c. voltage test can be carried out. Acid rain and $\mathrm{NH}_{4} \mathrm{Cl}$ solution were used as contaminants in the present study. The different flow rates were obtained using the control of the peristaltic pump. The d.c. voltage of $4.0 \mathrm{kV}$ was connected to the top electrode and the bottom electrode was solidly grounded. The same voltage level was maintained for the a.c. voltages in the study. The times to failure due to tracking arrived at once the arc inception took place near the bottom electrode and crossed 2/3 of the gap; otherwise the process lasted for $6 \mathrm{~h}$ and the experiment was properly terminated. For the purpose of comparison, the study was carried out under a.c. voltages at the same voltage level. The composition of the acid rain is provided in table 1 . In another set of experiments, the samples were aged by placing them in hot water bath maintained at different temperatures viz. 25, 60 and $90^{\circ} \mathrm{C}$. The samples were taken out and the contact angles were measured at required instant of time. The $\mathrm{pH}$ value of the contaminant was measured using Digital $\mathrm{pH}$ meter Model DI-707 and the conductivity measured using Lutron CD-4302.

The investigations on tracking were carried out with samples aged in water. The samples were immersed in
Table 1. Ingredients of artificial acid rain used in this experiment $(\mathrm{g} / 21)$.

\begin{tabular}{ll}
\hline $\mathrm{NH}_{4} \mathrm{Cl}$ & $1 \cdot 00$ \\
$\mathrm{NaCl}$ & $2 \cdot 55$ \\
$\mathrm{KCl}$ & $0 \cdot 18$ \\
$\mathrm{MgSO}_{4}$ & $1 \cdot 05$ \\
$\mathrm{CaSO}_{4} \cdot 2 \mathrm{H}_{2} \mathrm{O}$ & $0 \cdot 90$ \\
$\mathrm{Triton}_{-} \mathrm{X}-100$ & $0 \cdot 40$ \\
$\mathrm{HNO}_{3}$ & $0 \cdot 90$ \\
\hline
\end{tabular}

distilled water bath maintained at different temperatures for 15 days. In the present work, studies were carried out at 30,60 and $90^{\circ} \mathrm{C}$. The samples were taken out and measured for increase in weight, at required instant of time.

\subsection{Investigation of acid rain}

Generally speaking, due to dissolution of carbon monoxide present in the atmosphere, in the rain water, the normal and clean precipitation becomes acid rain. At $0^{\circ} \mathrm{C}$, under $1 \mathrm{~atm}$. pressure, and with saturated carbon monoxide, the $\mathrm{pH}$ value of normal precipitation is about 5.6. Acid rain is the one with $\mathrm{pH}$ value less than 5.6. The $\mathrm{SO}_{x}$ and $\mathrm{NO}_{x}$ and other contaminants, in atmosphere, dissolves in the rain to become sulphuric acid, nitric acid and the other form of acid (Butcher and Charlson 1992).

The root cause of acid rain mainly results from the use of coal and heavy oil fuels, the exhaust gas of the car and other origins of industrial pollution. The contaminants react with oxygen, in atmosphere, by UV ray, and dissolve in rain. The investigation of Metrology Bureau of Japan (IEC-publication-587 1984) identified the $\mathrm{SO}_{4}^{2-}, \mathrm{NO}_{3}^{-}, \mathrm{Cl}^{-}$, $\mathrm{NH}_{4}^{+}, \mathrm{Ca}^{2+}, \mathrm{K}^{+}, \mathrm{Mg}^{2+}$, and $\mathrm{Na}^{+}$as the constituents of acid rain.

\subsection{Characteristics of acid rain}

The important characteristics of acid rain are ion ingredients, $\mathrm{pH}$ value and conductivity. The three essential 
factors are related to each other. It is the ingredient and composition of acid rain which influence the $\mathrm{pH}$ value and conductivity. To understand the influence of acid rain on the performance of polymeric material, artificial acid rain was prepared in the laboratory. The composition of artificial acid rain as shown in table 1 agrees with that of actual acid rain (Hasegawa et al 1997). The $\mathrm{pH}$ value of artificial acid rain is 1.9 and its conductivity is adjusted to the required value.

\subsection{Contact angle measurement}

Various methods are available for determining the hydrophobicity of insulators. It has been shown that the contact angle measurement helps in understanding the hydrophobicity of the material. In the present work, the contact angle is measured by liquid droplet method, using distilled water, assuming constant radius of curvature and thereby determining contact angle from the measurement of height and base diameter for a known volume (Adamson 1976). After the distilled water is dropped on the surface, the contact angle measurement is carried out within $30 \mathrm{sec}$. The contact angle measured for the different types of specimen used is given in table 3.

\subsection{Physico-chemical analysis}

2.4a Wide angle X-ray diffraction (WAXD): In the present work, WAXD measurement was done with Phillips X-ray diffractometer. A scan rate of $2 \%$ min at 2000 cycles using $\mathrm{CuK}_{\alpha}$ radiation of wavelength $1.596 \AA$ was applied. A radial scan of Bragg angle $(2 \theta)$ vs intensity was obtained with an accuracy of $\pm 0 \cdot 25^{\circ}$ at the location of the peak.

2.4b Thermogravimetric-differential thermal analysis (TG-DTA): The TG and DTA are very effective techniques to study the chemical and physical phenomena as a function of temperature. The TG-DTA study was carried out with Netzch STA 409C equipment. The experiments were performed in nitrogen atmosphere, operated in the range $25-1200^{\circ} \mathrm{C}$ at a heating rate of $20^{\circ} \mathrm{C}$. Alumina was used as standard.

2.4c Differential scanning calorimetry (DSC): The melting behaviour of the specimen were observed using Netzch DSC 204 apparatus. The experiments were performed in nitrogen atmosphere, at a heating rate of $10^{\circ} \mathrm{C}$.

\section{Theoretical consideration}

\subsection{Theory of water diffusion and variation of contact angle measurement}

The diffusion coefficient of the distilled water into EPDM material was determined at different temperatures. Crank
(1975) developed the relationship, which represents the state of decreasing absorption of liquid into the material. When diffusion is driven by the concentration gradient and if there is no chemical change between liquid and material, they would result in mass change and the rate of absorption will be linear initially with $t^{0.5}$, where ' $t$ ' is the time of absorption. Hence

$$
\frac{\ddot{\mathrm{A}} m(t)}{\ddot{\mathrm{A}} m_{\alpha}}=2 \sqrt{\frac{D t}{t^{2}}}\left\{\left[\sqrt{\frac{1}{\partial}}+2 \sum_{n=1}^{\infty}\left[(-1)^{n} \cdot \operatorname{ierf}\left(\frac{n l}{2 \sqrt{D t}}\right)\right]\right]\right\},
$$

where $\Delta m(t)=m(t)-m(0)$ and $\Delta m_{\alpha}=m_{\alpha}-m(0)$. In this $m(t)$ is mass at time 'tr'. $m(0)$ and $m(\alpha)$ are initial mass at time ' $t$ ' and after infinite time, respectively. Crank (1975) provided final equation to calculate diffusion coefficient and if the linear dependency in plot $\Delta m(t) / \Delta m(\alpha)$ vs $t^{0.5}$ is not observed, then the diffusion constant is obtained by equating $\Delta m(t) / \Delta m_{\alpha}=0 \cdot 5$.

Simplifying the equation we get

$$
D=\frac{\partial}{64} \frac{L_{0.5}^{2}}{t_{0.5}}
$$

where $L$ is the thickness of the specimen.

\section{Tracking process}

When high voltage is connected to the top electrode, current flows in the conductive path formed by the contaminant (between top and bottom electrode) and causes partial evaporation of the contaminant causing dry band in the gap. The potential difference between dry band incepts spark across the dry band. Continuous flow

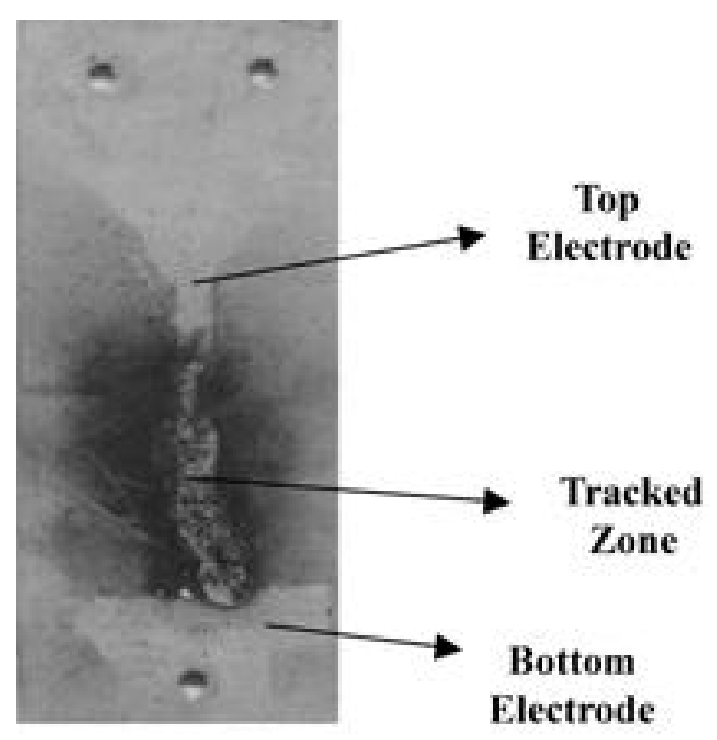

Figure 2. Tracking formed zone. 
of contaminant in the gap rewet the surface and the above process is repeated. The spark across the dry band results in slow rise of surface temperature and gradual heating of the specimen. The high temperature of the arc in the gap as well as the high temperature due to possible reaction of $\mathrm{NH}_{4} \mathrm{Cl} /$ acid rain with the EPDM material is considered to be responsible for erosion of material followed with tracking process. Sometimes the arc burning across the gap is extinguished by the flow of contaminants and the entire process detailed above restarts.

However, accumulation of the contaminants in the gap, over a period of time, permits more current to flow in the conductive path formed by the contaminant at the same applied voltage. Therefore, the entire process is accelerated so that heavy burning takes place between the electrodes causing carbonized path as shown in figure 2 . This phase is identified as 'failure due to tracking'.

\section{Results and discussion}

Figure 3 shows variation in tracking time of the unaged EPDM specimen under a.c. and d.c. voltages with different contaminants, at different conductivity levels. It is observed that under positive d.c. voltage the tracking time is high irrespective of the level of conductivity and the type of contaminant used in the present work. Similar characteristics were observed by Sarathi et al (2000a) with epoxy resin insulation and the converse with HDPE material under the d.c. voltages (Sarathi et al 2000b). It indicates that the tracking phenomena depend on the conductivity level of the contaminant and the type of material. It is also observed that under a.c. voltages no degradation has occurred with acid rain as contaminant. This indicates the severity of the contaminant on the insulation structure when it is operated under the d.c. voltages. Comparing the tracking time with ammonium chloride and acid rain as contaminants, it is observed that irrespective of type of voltage a.c. or d.c. voltages, the tracking time is high with acid rain as contaminant compared to ammonium chloride solution especially at lower conductivity levels.

Figure 4 shows variation in the tracking of the EPDM specimen under the a.c./d.c. voltages with $\mathrm{NH}_{4} \mathrm{Cl} /$ acid rain as contaminant of conductivity $2500 \mu \mathrm{S}$, at different flow rates. It is observed that increase in flow rate shows increase in the tracking time of the specimen under the a.c. voltages with $\mathrm{NH}_{4} \mathrm{Cl}$ as contaminant and no tracking has occurred for $6 \mathrm{~h}$ with the acid rain as contaminant. When the flow rate is increased the tracking time increased under the negative d.c. voltages compared to positive d.c. voltages especially with $\mathrm{NH}_{4} \mathrm{Cl}$ as contaminant. With the acid rain as the contaminant, increase in flow rate does not show any polarity dependence on the tracking time.

Table 2 shows variation in diffusion coefficient of the material aged in distilled water solution maintained at different temperatures. The diffusion coefficient of the material is not constant at different temperatures. Table 3 shows variation in tracking time of the EPDM specimen (aged under different conditions) under the a.c. and d.c. voltages with $\mathrm{NH}_{4} \mathrm{Cl} /$ acid rain (of $2500 \mu \mathrm{S}$ ) as contaminant. Under the a.c. voltages, irrespective of the type of ageing, the samples continued without tracking for $6 \mathrm{~h}$ especially with $\mathrm{NH}_{4} \mathrm{Cl}$ as contaminant. Under the d.c. voltages, it is observed that the tracking time is high with positive d.c. voltage irrespective of the type of contami-

Table 2. Variation in diffusion coefficient of the material.

\begin{tabular}{lc}
\hline Ageing condition & Diffusion coefficient \\
\hline Aged in water at $30^{\circ} \mathrm{C}$ & $1.75 \times 10^{-12}$ \\
Aged in water at $60^{\circ} \mathrm{C}$ & $1.96 \times 10^{-12}$ \\
Aged in water at $90^{\circ} \mathrm{C}$ & $1.29 \times 10^{-12}$ \\
\hline
\end{tabular}
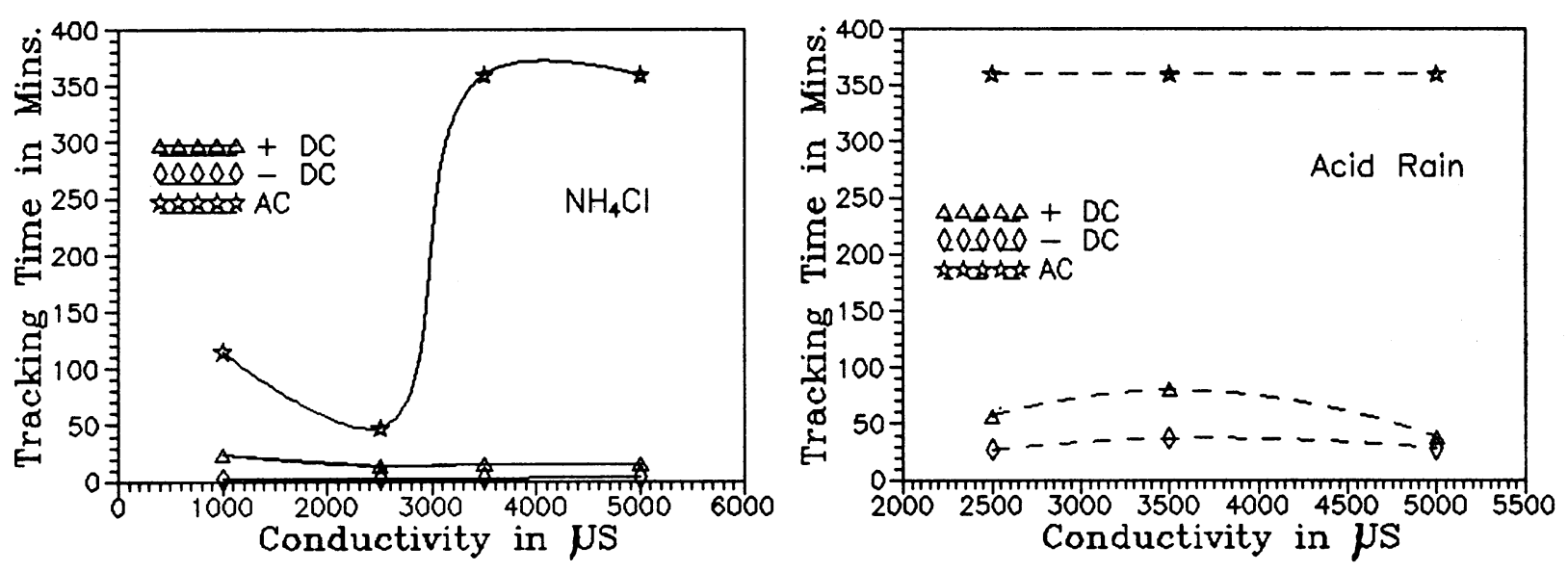

Figure 3. Variation in tracking time of unaged EPDM specimen under a.c. and d.c. voltages at different conductivities of the contaminant. 

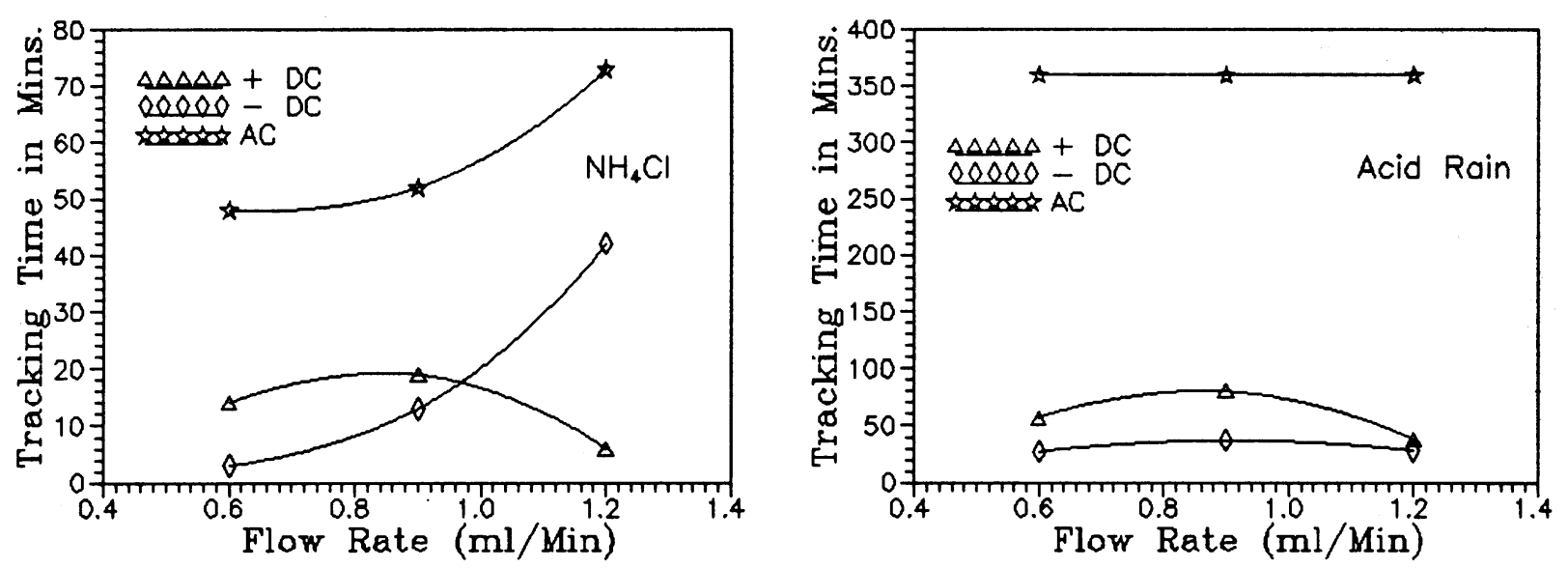

Figure 4. Variation in tracking time of unaged EPDM specimen under a.c. and d.c. voltages at different flow rates of the contaminant.

Table 3. Tracking time, contact angle $(\theta)$ and surface roughness $(\chi)$ of the aged specimen.

\begin{tabular}{|c|c|c|c|c|c|c|c|c|}
\hline \multirow[b]{2}{*}{ Ageing condition } & \multicolumn{3}{|c|}{$\begin{array}{c}\mathrm{NH}_{4} \mathrm{Cl} \\
\text { Tracking time (min) }\end{array}$} & \multicolumn{3}{|c|}{$\begin{array}{c}\text { Acid rain } \\
\text { Tracking time (min) }\end{array}$} & \multirow[b]{2}{*}{$\theta(\operatorname{Deg})$} & \multirow[b]{2}{*}{$\chi(\mu \mathrm{m})$} \\
\hline & + D.C. & - D.C. & A.C. & + D.C. & - D.C. & A.C. & & \\
\hline Aged in water at $30^{\circ} \mathrm{C}$ & 53 & 5 & NF & 82 & 29 & 165 & 83 & 1.63 \\
\hline Aged in water at $60^{\circ} \mathrm{C}$ & 41 & 29 & $\mathrm{NF}$ & 76 & 41 & NF & 76 & 1.52 \\
\hline Aged in water at $90^{\circ} \mathrm{C}$ & 47 & 48 & NF & 82 & 56 & NF & 68 & $4 \cdot 41$ \\
\hline
\end{tabular}

$\theta$ : contact angle; $\chi$ : surface roughness; NF: no failure.

nant. From table 3, the surface roughness of the material increases for the aged samples and is high for the water aged samples especially at high temperatures. In the acid aged samples, the surface roughness is high for the oxalic acid aged samples.

The measure of hydrophobicity could be analysed using the contact angle variation. If the contact angle of the material increases above $90^{\circ}$, it shows that the material is hydrophobic and if the value is less than $90^{\circ}$, it shows that the material is hydrophilic (Crank 1975). The contact angle reduces for the aged samples. The contact angle is the minimum for the sample aged in temperature controlled water bath maintained at $90^{\circ} \mathrm{C}$. The values of the surface roughness is the average of the values obtained at five different locations. The value of surface roughness and the contact angle of the virgin EPDM material is $1.29 \mu \mathrm{m}$ and $84^{\circ}$, respectively.

During the tracking process, we could differentiate carbon formation with different colours, viz. a portion with dark black and white. Especially at the tip of the tracked form zone white powder is formed. To analyse the carbonized path, in the present work, WAXD technique was utilized. Figure 5 shows variation in the WAXD

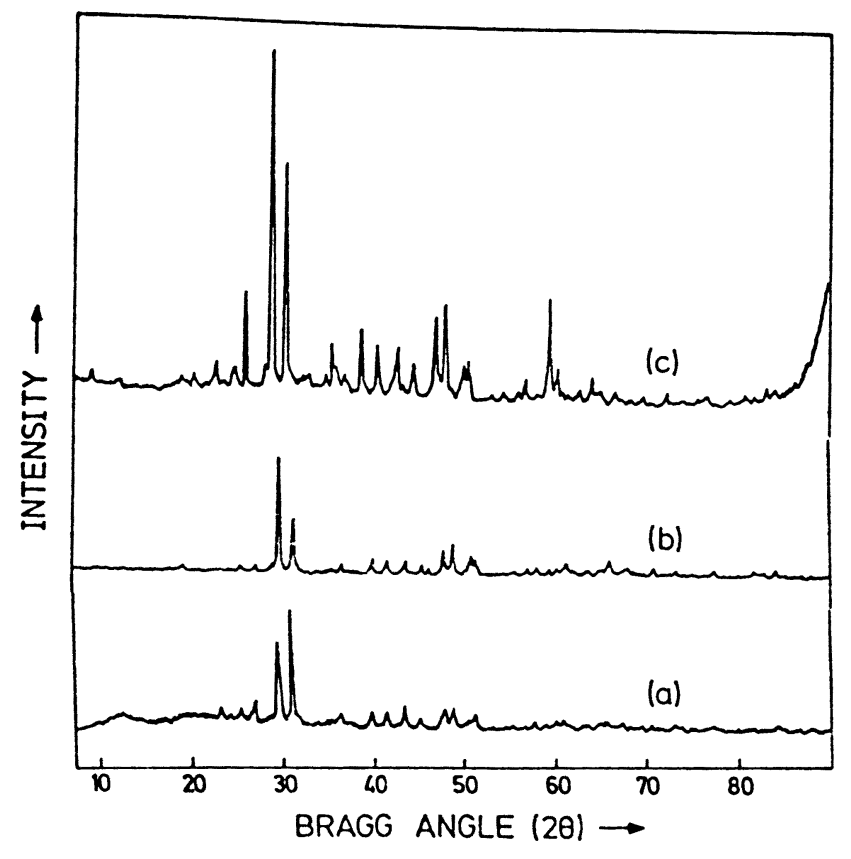

Figure 5. WAXD spectra of EPDM: (a) virgin, (b) tracked surface and (c) residue of tracking. 
pattern obtained for the EPDM rubber, surface of the tracked zone and the residue obtained due to tracking. It is possible to identify difference in the spectrum. It indicates that the characteristics of the material are altered near the tracking formed zone and further analysis is required on this aspect.

Differential scanning calorimetry is a technique in which the difference in energy input into a material and a reference material is measured as a function of temperature. Figure 6 shows the DSC spectra of the virgin EPDM material and the tracking formed zone material. It is clear that the thermogram is different for the virgin and tracking formed zone material. The curve indicates the glass transition temperature at $-70^{\circ} \mathrm{C}$ and at $-25^{\circ} \mathrm{C}$ for the virgin EPDM and at $-98^{\circ} \mathrm{C}$ and $4.8^{\circ} \mathrm{C}$, when heated between $-130^{\circ}$ and $150^{\circ} \mathrm{C}$ at $10^{\circ} \mathrm{C} / \mathrm{min}$. In addition, in

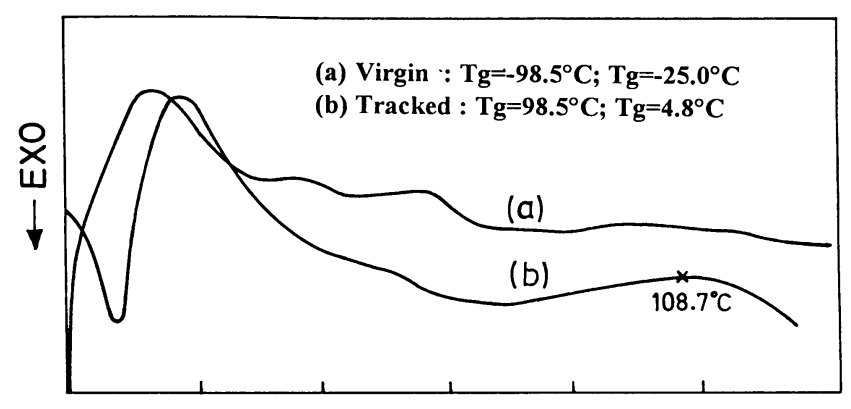

TEMPERATURE $\left({ }^{\circ} \mathrm{C}\right)$

Figure 6. DSC thermogram.

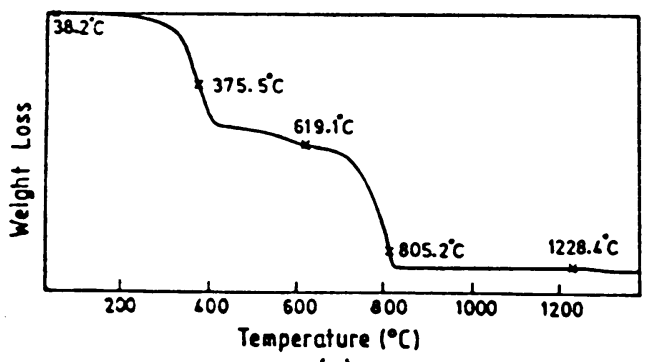

(a)

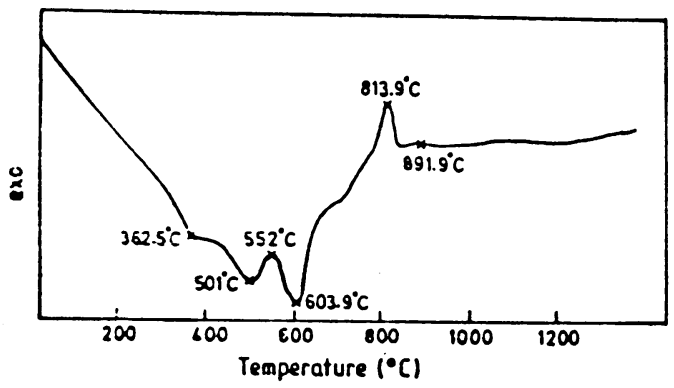

(c) the tracking formed zone material a endothermic peak at $108.7^{\circ} \mathrm{C}$ is observed. The variation in the glass transition temperatures and the addition of the endothermic peak in the tracking formed zone material indicate that the characteristics of the material is altered near the tracking formed zone.

Figure 7 shows the TG and DTA thermogram of the EPDM and the microtomed section of the tracking formed zone. These measurements are used primarily to determine the composition of materials and to predict their thermal stability. In the nitrogen atmosphere, the TG curve (figure 7a) for EPDM shows a gradual weight loss above $200^{\circ} \mathrm{C}$. The derivative curve indicates that the weight loss occurs at two different temperatures especially at $375^{\circ} \mathrm{C}$ and $805^{\circ} \mathrm{C}$. The TG curve of microtomed section of tracking formed zone (figure $7 \mathrm{~b}$ ) shows a different characteristics and the weight loss of the specimen occurs at $786^{\circ} \mathrm{C}$. It is the indication that structural variation has occurred in the surface during tracking process. The DTA spectra (figure 7c) indicate endothermic peaks at $552^{\circ} \mathrm{C}$ and $813^{\circ} \mathrm{C}$. The exothermic peaks were observed at $501{ }^{\circ} \mathrm{C}$ and $603^{\circ} \mathrm{C}$ for the EPDM specimen. In the case of microtomed section of the tracking formed zone specimen (figure 7d), two exothermic peaks at $585^{\circ} \mathrm{C}$ and $796^{\circ} \mathrm{C}$ and the endothermic peaks at $498^{\circ} \mathrm{C}$, $645^{\circ} \mathrm{C}$ and $818^{\circ} \mathrm{C}$ were observed. Normally the endothermic peaks indicate the weight loss of the specimen due to dehydration or decomposition. It is observed from figures $7 \mathrm{c}$ and $\mathrm{d}$, that the considerable weight loss observed at around $820^{\circ} \mathrm{C}$ in the virgin EPDM and at around $790^{\circ} \mathrm{C}$ in the case of tracking formed zone, is the

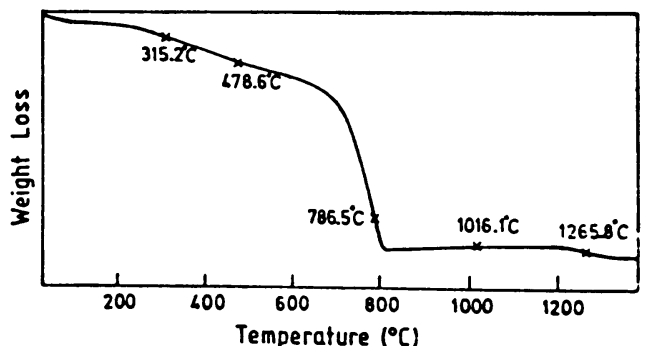

(b)

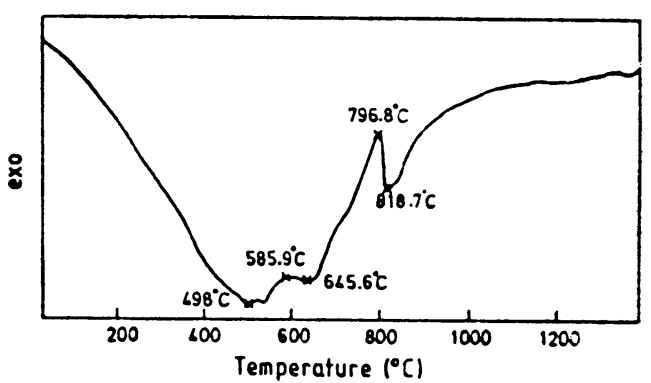

(d)

Figure 7. TG-DTA spectra of EPDM material: (a) TG spectra of virgin, (b) TG spectra of tracked surface, (c) DTA spectra of virgin and (d) DTA spectra of tracked surface. 
indication that the thermal characteristics of the material is altered in the tracking formed zone.

\section{Conclusions}

The tracking time is less under the d.c. voltages compared to a.c. voltage, irrespective of the type of contaminant and ageing condition. This shows the severity of the d.c. voltage on the outdoor structure insulators under polluted condition. It is observed that the tracking time is high when the positive d.c. voltage is connected to the top electrode especially when the conductivity of the contaminant is less. The increase in flow rate of the contaminant reduces the tracking time of the specimen especially with positive d.c. voltage. The diffusion coefficient of the sample varies when the samples are aged in water bath maintained at high temperatures.

Tracking time is high with the positive d.c. voltages compared to negative d.c. voltages irrespective of the type of the contaminant (acid rain/ $\mathrm{NH}_{4} \mathrm{Cl}$ ). The surface roughness and the contact angle measurement vary with the type of ageing and indicate degree of severity. The WAXD studies show characteristic change in the material near the tracking formed zone. The DSC and TG-DTA studies indicate that thermal characteristics of the material near the tracking formed zone are altered which indicates that the tracking process is surface degradation process.

\section{References}

Adamson A W 1976 Physical chemistry of surfaces (New York: John Wiley \& Sons) 5 th ed.

Butcher S S and Charlson R J 1992 An introduction to air chemistry (New York: Academic Press Inc.)

Crank J 1975 Mathematics of diffusion (Oxford: Clarendon) 2nd ed.

Deng Hui and Hackam R 2000 IEEE Trans. Dielectr. \& Electr. Insul. 784

Hasegawa Seiichi et al 1997 The influence of acid rain on the tracking deterioration of organic insulating materials, Proc. of the 5th ICPADM, Seoul, Korea pp 754-758

IEC-Publication-587 1984 Test method for evaluating the resistance of tracking and the erosion of electrical insulating materials used under severe ambient condition

Sarathi $\mathrm{R}$ et al 2000a Investigations of tracking phenomena in HDPE material due to acid rain under d.c. voltages, section IV, INSULEC-2000, IEEMA, Hyderabad

Sarathi R et al 2000b Study of the effect of filler on the hydrophobicity characteristics of epoxy resin aged under saline solution, in Recent advances in polymers and composites (eds) G N Mathur, L D Kandpal and A K Sen (New Delhi: Allied Publishers Ltd.) pp 612-616

Yoshimura N et al 1997 IEEE Electr. Insul. Mag. 88 